\title{
Induction of molecular chaperones in carbon tetrachloride-treated rat liver: implications in protection against liver damage
}

\author{
Kwang-Jong Lee, ${ }^{1,2}$ Kazutoyo Terada, ${ }^{1}$ Seiichi Oyadomari, ${ }^{1}$ Yukihiro Inomata, ${ }^{2}$ Masataka Mori, ${ }^{1}$ \\ and Tomomi Gotoh'
}

1Department of Molecular Genetics, Graduate School of Medical Sciences, Kumamoto University, Honjo 1-1-1, Kumamoto 860-8556, Japan

${ }^{2}$ Department of Pediatric Surgery, Graduate School of Medical Sciences, Kumamoto University, Honjo 1-1-1, Kumamoto 860-8556, Japan

\begin{abstract}
Carbon tetrachloride $\left(\mathrm{CCl}_{4}\right)$ induces liver damage, apparently through the formation of free-radical metabolites. Molecular chaperones such as heat shock protein (Hsp) of $70 \mathrm{kDa}$ have been found to protect cells from various stresses. We previously found that cytosolic chaperone pairs of the Hsp70 family and their DnaJ homolog cochaperones prevent nitric oxide-mediated apoptosis and heat-induced cell death. Expression of cytosolic chaperones, including Hsp70; heat shock cognate (Hsc) 70; and DnaJ homologs dj1 (DjB1/Hsp40/hdj-1), dj2 (DjA1/HSDJ/hdj-2), dj3 (DjA2), and dj4 (DjA4), in the liver of $\mathrm{CCl}_{4}$-treated rats was analyzed. Messenger ribonucleic acids for all these chaperones were markedly induced 3-12 hours after $\mathrm{CCl}_{4}$ treatment with a maximum at 6 hours. Hsp70 and dj1 proteins were markedly induced at 6-24 hours with a maximum at 12 hours, whereas dj2 and dj4 were moderately induced at around 12 hours. Hsc70 was weakly induced after treatment, and dj3 was little induced. To better understand the significance of the induction of chaperones, the effect of preinduction of chaperones on $\mathrm{CCl}_{4}$-induced liver damage was analyzed. When chaperones were preinduced in the liver by heat treatment, increase in serum alanine aminotransferase activity after $\mathrm{CCl}_{4}$ treatment was significantly attenuated. Hsp90, another major cytosolic chaperone, also was induced by heat treatment. On the other hand, $\mathrm{Mn}$ - and $\mathrm{Cu} / \mathrm{Zn}$-superoxide dismutase were not induced by heat treatment or by $\mathrm{CCl}_{4}$ treatment. These results suggest that cytosolic chaperones of Hsp70 and DnaJ families or Hsp90 (or both) are induced in $\mathrm{CCl}_{4}$-treated rat liver to protect the hepatocytes from the damage being inflicted.
\end{abstract}

\section{INTRODUCTION}

Heat shock proteins (Hsps) are induced in response to various stresses and to protect cells from such stresses (Kampinga 1993; Parsell and Lindquist 1993; Samali and Orrenius 1998; Smith et al 1998). Major Hsps are relegated into several groups on the basis of both size and function. Some Hsps are constitutively expressed and act as molecular chaperones. Members of the Hsp70 family are involved in the folding and intracellular transport of newly synthesized proteins (Lindquist and Craig 1988; Johnson and Craig 1997; Netzer and Hartl 1998). To protect cells from various stresses, Hsp70s bind to damaged

\footnotetext{
Received 14 May 2003; Revised 23 October 2003; Accepted 23 October 2003.

Correspondence to: Tomomi Gotoh, Tel: 81-96-373-5140; Fax:81-96-373-5145; E-mail: tomomi@gpo.kumamoto-u.ac.jp.
}

and misfolded proteins and facilitate their refolding or target severely damaged proteins for degradation (Kampinga 1993; Stege et al 1994; Samali and Orrenius 1998). DnaK, which is the Hsp70 homolog of Escherichia coli, is regulated by other molecular chaperones, DnaJ and GrpE (Parsell and Lindquist 1993; Netzer and Hartl 1998). Several mammalian DnaJ homologs (Hsp40 family members) were identified (Ohtsuka and Hata 2000) and have been shown to regulate Hsp70 family members. Major DnaJ homologs in mammalian cytosol are dj1 (DjB1/Hsp40/ hdj-1), dj2 (DjA1/HSDJ/hdj-2), and dj3 (DjA2). We found that heat shock cognate (Hsc) $70-\mathrm{dj} 2$ or dj3 rather than Hsc70-dj1 facilitates mitochondrial protein import and luciferase refolding (Terada et al 1997; Terada and Mori 2000). We also found that both Hsp70-dj1 and Hsp70-dj2 chaperone pairs are effective in preventing nitric oxide- 


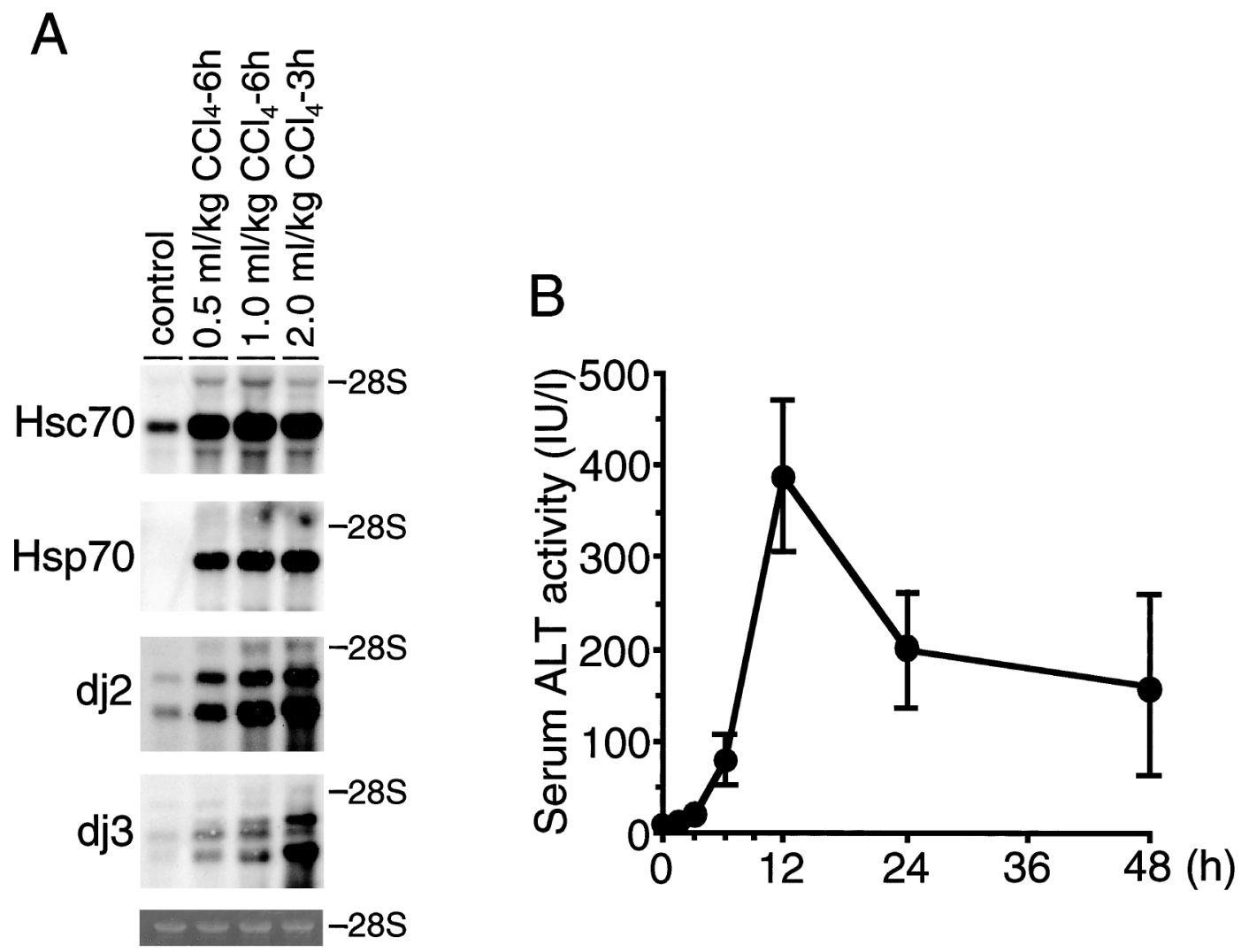

Fig 1. Induction of messenger ribonucleic acid (mRNAs) for molecular chaperone in the carbon tetrachloride $\left(\mathrm{CCl}_{4}\right)$-treated rat liver. $(\mathrm{A})$ Rats were given intraperitoneally various amounts of $\mathrm{CCl}_{4}$, as indicated on the top. Total RNA was isolated from the rat liver at indicated times after $\mathrm{CCl}_{4}$ injection. RNAs $(2.25 \mu \mathrm{g})$ were subjected to blot analysis for Hsc70, Hsp70, dj2, and dj3 mRNAs as described in the Materials and Methods. Control RNA was total RNA from vehicle-treated rat liver. The positions of 28S ribosomal RNA (rRNA) are shown on the right. The bottom panel shows ethidium bromide staining of $28 \mathrm{~S}$ rRNAs. (B) Serum ALT activities were measured at indicated times after CCl $(1.0 \mathrm{~mL} / \mathrm{kg})$ injection, and the results are shown as means \pm SE $(n=3)$. ALT, alanine aminotransferase; Hsc70, heat shock cognate 70 ; Hsp70, heat shock protein 70 .

mediated apoptosis in RAW 264.7 macrophages (Gotoh et al 2001). Recently, we characterized another cytosolic DnaJ family member dj4 (DjA4), which is highly expressed in the heart, and showed that the Hsp70-dj4 chaperone pair prevents cells from severe heat-induced cell death (Abdul et al 2002).

Carbon tetrachloride $\left(\mathrm{CCl}_{4}\right)$-treated rats are widely used to study liver damage. $\mathrm{CCl}_{4}$ was reported to induce not only necrosis but also apoptosis in rat liver (Shi et al 1998; Sun et al 2001). Although the mechanism by which $\mathrm{CCl}_{4}$ causes liver damage is unclear, several lines of evidence suggest that the liver damage can be caused by free-radical metabolites (Williams and Burk 1990). $\mathrm{CCl}_{4}$ is converted to the trichloromethyl radical by cytochrome $P-450$ through a 1-electron reduction. A fatty acid radical is generated by the reaction between trichloromethyl radical and unsaturated fatty acids, and lipid peroxidation follows. This lipid peroxidation leads to malfunction of cell membranes and intracellular organelle membranes.

We now report that cytosolic molecular chaperones are induced in the liver of $\mathrm{CCl}_{4}$-treated rats and that this
$\mathrm{CCl}_{4}$-induced liver damage is attenuated by preinduction of chaperones by heat treatment.

\section{MATERIALS AND METHODS}

\section{Materials}

Monoclonal antibodies against Hsc70 (cognate form) and Hsp70 (inducible form) were obtained from Santa Cruz Biotechnology Inc (Santa Cruz, CA, USA). Polyclonal antibodies against dj1, Mn-superoxide dismutase (SOD), and $\mathrm{Cu} / \mathrm{Zn}-\mathrm{SOD}$ and monoclonal antibody against Hsp90 were obtained from StressGen Biotechnologies Corp (Victoria, Canada). This anti-Hsp90 antibody detects both $\mathrm{Hsp} 90 \alpha$ and Hsp90ß. Polyclonal antibodies against dj2 (Terada et al 1997), dj3 (Terada and Mori 2000), dj4 (Abdul et al 2002), and argininosuccinate lyase (AL) (Yu et al 1995) were as reported.

\section{Animals and treatment}

All procedures involving animals were approved by the Animal Care and Use Committee of Kumamoto Univer- 
A
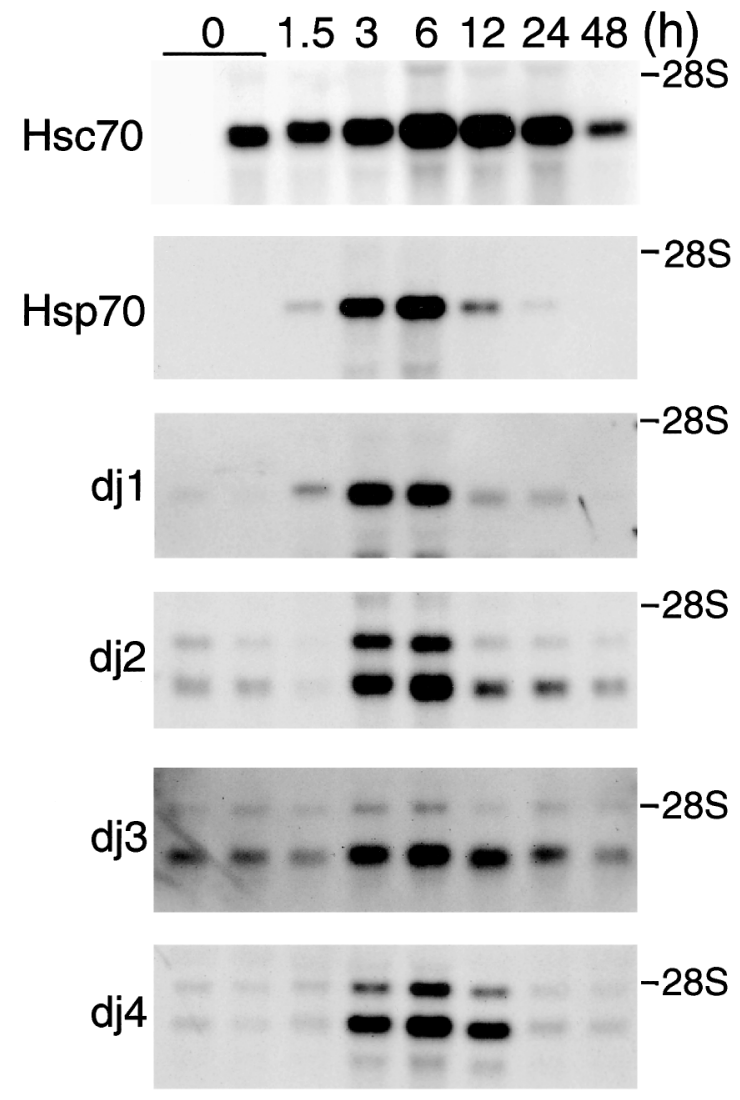

$-28 \mathrm{~S}$
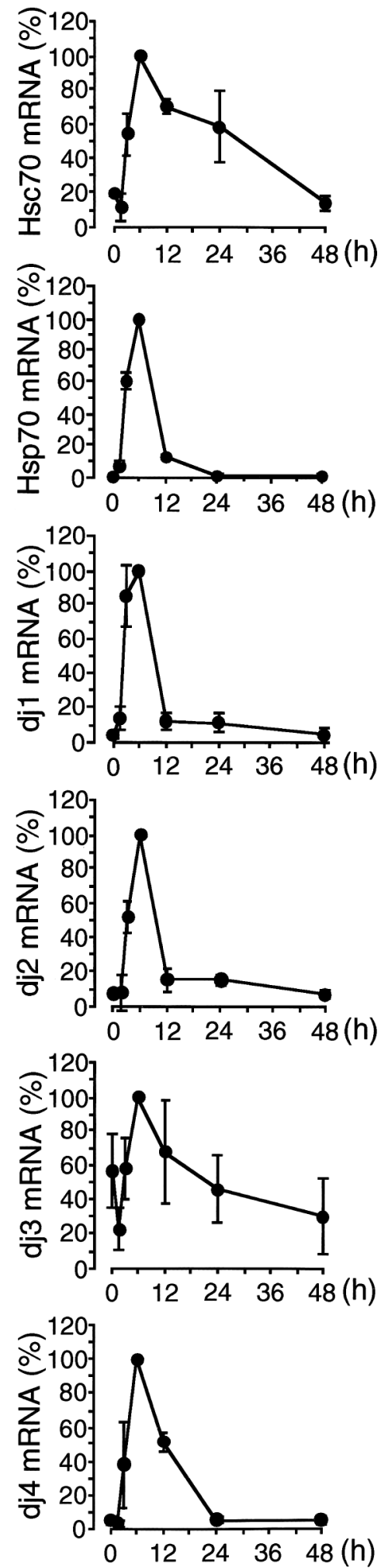

Fig 2. Time course of induction of mRNAs for Hsc70, Hsp70, dj1, dj2, dj3, and dj4 in the carbon tetrachloride $\left(\mathrm{CCl}_{4}\right)$-treated rat liver. (A) Total ribonucleic acids (RNAs) were isolated from rat livers at indicated times after $\mathrm{CCl}_{4}(1.0 \mathrm{~mL} / \mathrm{kg})$ injection. RNAs $(2.25 \mu \mathrm{g})$ were subjected to blot analysis. The positions of 28S ribosomal RNA ( $R$ RNA) are shown on the right. The bottom panel shows ethidium bromide staining of $28 \mathrm{~S}$ rRNA. (B) Results in (A) were quantified and are shown as means \pm SD $(n=3)$. Maximal values are set at $100 \%$. Hsc70, heat shock cognate 70; Hsp70, heat shock protein 70; mRNA, messenger ribonucleic acid. 

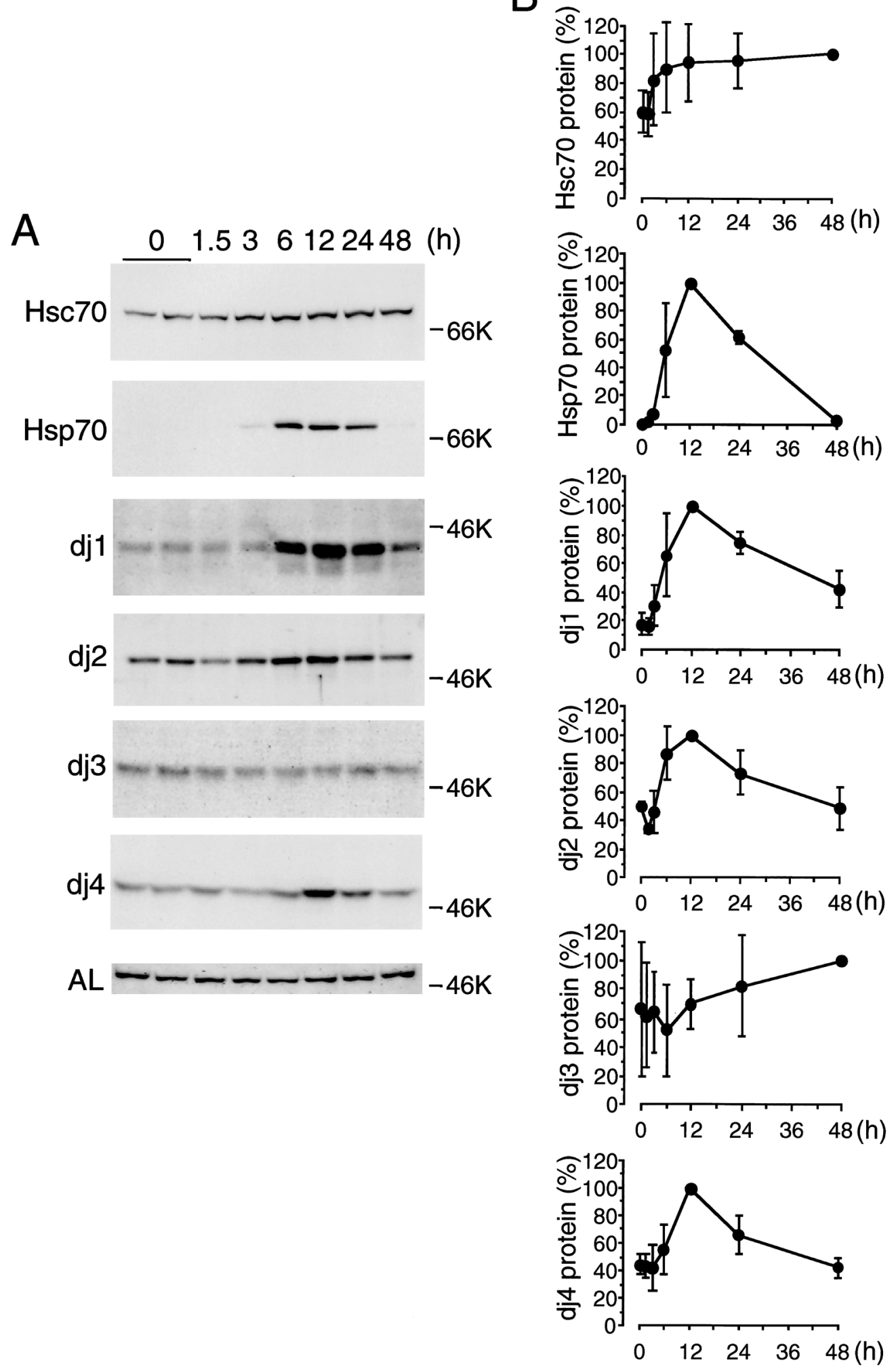

Fig 3. Time course of induction of heat shock cognate (Hsc) 70 , heat shock protein (Hsp) 70 , dj1, dj2, dj3, dj4, and argininosuccinate lyase (AL) proteins in the carbon tetrachloride $\left(\mathrm{CCl}_{4}\right)$-treated rat liver. (A) Liver extracts (10 $\mu \mathrm{g}$ of protein for Hsc70, $\mathrm{Hsp} 70$, dj1, dj2, and $\mathrm{AL}$; 50 $\mu \mathrm{g}$ of protein for dj3 and dj4) prepared at indicated times were subjected to immunoblot analysis for Hsc70, Hsp70, dj1, dj2, dj3, dj4, and AL. AL served as control. Molecular weight markers are bovine serum albumin (66 kDa) and ovalbumin (46 kDa). (B) Results in (A) were quantified and are shown as means $\pm \operatorname{SD}(n=3)$. Maximal values are set at $100 \%$. 


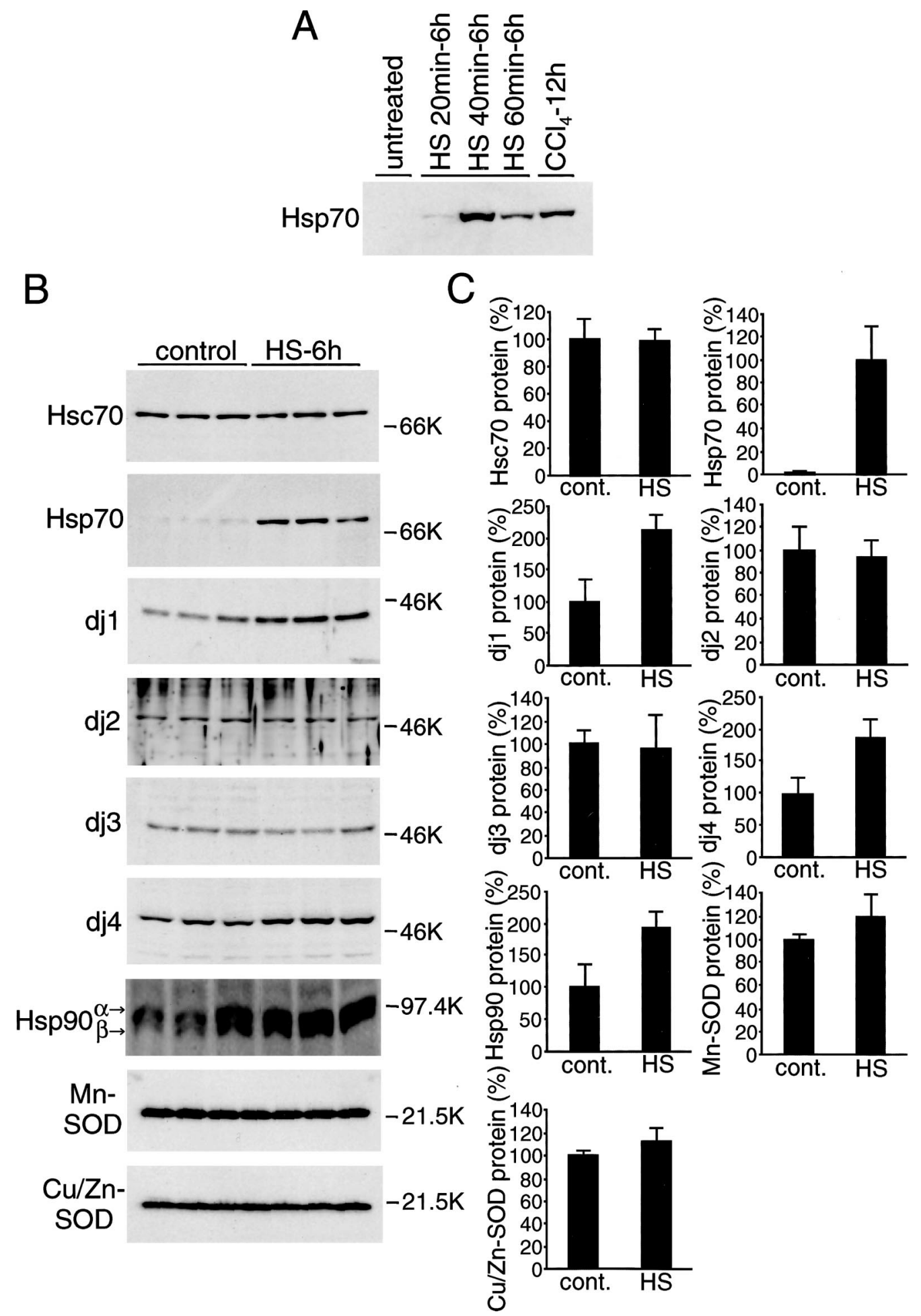

Fig 4. Induction of heat shock protein (Hsp) 70 and DnaJ chaperones in the liver by whole body heat treatment. (A) Rats were heated at $42^{\circ} \mathrm{C}$ in waterbath for indicated periods and allowed to recover at room temperature for 6 hours. Liver extracts (10 $\mu \mathrm{g}$ of protein) were subjected to immunoblot analysis for Hsp70. Extracts from rat liver $\left(10 \mu \mathrm{g}\right.$ of protein) 12 hours after carbon tetrachloride $\left(\mathrm{CCl}_{4}\right)$ injection were included for comparison. (B) Rats were heated at $42^{\circ} \mathrm{C}$ for 40 minutes and allowed to recover at room temperature for 6 hours. Liver extracts (10 $\mu \mathrm{g}$ of protein for heat shock cognate [Hsc] 70, Hsp70, dj1, dj2, Hsp90, Mn-superoxide dismutase [SOD], and Cu/Zn-SOD; $50 \mu \mathrm{g}$ of protein for dj3 and dj4) were subjected to immunoblot analysis for Hsc70, Hsp70, dj1, dj2, dj3, dj4, Hsp90, Mn-SOD, and Cu/Zn-SOD. Liver extracts from untreated rats were used as control. Molecular weight markers are phosphorylase B (97.4 kDa), bovine serum albumin (66 $\mathrm{kDa})$, ovalbumin $(46 \mathrm{kDa})$, and trypsin inhibitor $(21.5 \mathrm{kDa})$. (C) The results in (B) were quantified and are shown by means \pm SD $(n=3)$. Values without heat treatment are set at $100 \%$, except for Hsp70, for which the value after heat treatment is set at $100 \%$. 
sity. Specific pathogen-free male Wistar rats (160-190 g, 6 weeks of age) were given $\mathrm{CCl}_{4}$ intraperitoneally (Wako Pure Chemical Industries, Osaka, Japan) after it had been dissolved in olive oil ( $1 \mathrm{~mL}$ total volume). For heat treatment, rats were placed in a temperature-controlled water bath to maintain the rectal temperature at $42^{\circ} \mathrm{C}$ for 40 minutes with the rats under anesthetization with thiopental (50 mg/kg body weight, intraperitoneally). Rats were killed by cutting abdominal aorta and inferior vena cava under anesthetization with thiopental.

\section{Measurement of serum alanine aminotransferase activity}

Blood samples were obtained from the inferior vena cava, then centrifuged at $500 \times g$ for 20 minutes. The serum fractions were used for the measurement of enzyme activity. Alanine aminotransferase (ALT) activity was measured using the GPT UV Test Wako kit (Wako Pure Chemical Industries) according to the protocol provided by the manufacturer.

\section{Northern blot analysis}

Total ribonucleic acid (RNA) from rat liver was prepared according to the acid guanidium thiocyanate-phenolchloroform extraction procedure (Chomczynski and Sacchi 1987). The RNAs (2.25 $\mu \mathrm{g}$ ) were electrophoresed in denaturing formaldehyde-containing agarose $(1 \%)$ gels and transferred to nylon membranes. Hybridization was performed using digoxigenin (DIG)-labeled antisense RNAs as probes. DIG-labeled antisense RNA probes were synthesized using a DIG RNA labeling kit (Roche Molecular Biochemicals, Indianapolis, IN, USA) with complementary deoxyribonucleic acid templates for Hsc70 (nt 1630-1979; GenBank accession number M19141), Hsp70 (nt 2894-3911; GenBank accession number X74271), dj1 (nt 226-775; GenBank accession number AB028272), dj2 (nt 390-989; GenBank accession number U53922), dj3 (nt 336-991; GenBank accession number U95727), and dj4 (nt 4-1315; GenBank accession number AB032401). Chemiluminescence signals derived from hybridized probes were detected using a DIG luminescence detection kit (Roche Molecular Biochemicals) and were quantified using a chemiluminescence image analyzer Las-1000 Plus (Fuji Photo Film Co, Tokyo, Japan).

\section{Immunoblot analysis}

Rat liver was homogenized in lysis buffer $(300 \mathrm{mM} \mathrm{NaCl}$, $50 \mathrm{mM}$ Tris- $\mathrm{HCl}, 1 \%$ Triton X-100, pH 7.5). After centrifugation, the supernatants served as tissue extracts. Immunoblot analysis was done as described (Oyadomari et al 2001). Immunodetection was performed using an ECL kit (Amersham Life Science, Buckinghamshire, UK), according to the protocol provided by the manufacturer. The chemiluminescence signals were quantified using Las-1000 Plus.

\section{RESULTS}

\section{Induction of cytosolic chaperone of Hsp70 and DnaJ families in $\mathbf{C C l}_{4}$-treated rat liver}

In preliminary experiments, we injected intraperitoneally $0.5,1.0$, and $2.0 \mathrm{~mL} / \mathrm{kg}$ body weight of $\mathrm{CCl}_{4}$ into rats. Next, we examined viability of animals and analyzed induction of messenger RNAs (mRNAs) for Hsc70, Hsp70, dj2, and dj3 in the liver 6 hours after injection (Fig 1A). Rats injected with $2.0 \mathrm{~mL} / \mathrm{kg}$ died within 6 hours; therefore, RNAs were measured 3 hours after injection. In control livers, mRNAs for Hsc70, dj2, and dj3 were expressed, whereas Hsp70 mRNA was not detected. All mRNAs were markedly induced by $\mathrm{CCl}_{4}$ at $1.0 \mathrm{~mL} / \mathrm{kg}$ and further increased at $2.0 \mathrm{~mL} / \mathrm{kg}$. Similar induction of mRNAs for Hsc70, Hsp70, and dj2 by $\mathrm{CCl}_{4}$ at $2.0 \mathrm{~mL} / \mathrm{kg}$ at 3 hours was observed, whereas dj3 mRNA was more strongly induced than the level at $1.0 \mathrm{~mL} / \mathrm{kg}$ at 6 hours. Thus, $\mathrm{CCl}_{4}$ at $1.0 \mathrm{~mL} / \mathrm{kg}$ was used in the following experiments.

ALT catalyzes the reversible transamination between alanine and 2-oxoglutarate to form pyruvate and glutamate. Serum ALT activity is used as an index of hepatocyte destruction. Time course of serum ALT activity was measured as the marker of liver damage under these conditions (Fig 1B). Serum ALT activity began to increase 6 hours after $\mathrm{CCl}_{4}$ injection, reached a maximum at 12 hours, and then decreased. These results show that destruction of hepatocytes is most severe from 6 to 12 hours after $\mathrm{CCl}_{4}$ injection.

Figure 2 shows the time courses of induction of mRNAs for Hsc70, Hsp70, dj1, dj2, dj3, and dj4 in the liver of $\mathrm{CCl}_{4}$-injected rats. Hsc70 mRNA began to increase at 3 hours after treatment, reached a maximum at 6 hours, then decreased, and returned to a control level at 48 hours. This marked induction of Hsc70 mRNA is noteworthy because such induction has not been reported in any other stress conditions. Hsp70 mRNA began to increase at 3 hours after treatment, reached a maximum at 6 hours, markedly decreased at 12 hours, and was not detectable at 24 hours. The time course for the induction of dj1 and dj2 mRNAs was similar to that of Hsp70. mRNAs for dj3 and dj4 began to increase at 3 hours after injection and reached a maximum at 6 hours like Hsp70 mRNA but decreased more slowly than Hsp70 mRNA.

Figure 3 shows the time course for induction of Hsc70, $\mathrm{Hsp} 70, \mathrm{dj} 1, \mathrm{dj} 2, \mathrm{dj} 3$, and dj4 proteins in the liver of $\mathrm{CCl}_{4^{-}}$ treated rats. Hsc70 protein, which was expressed before 
A

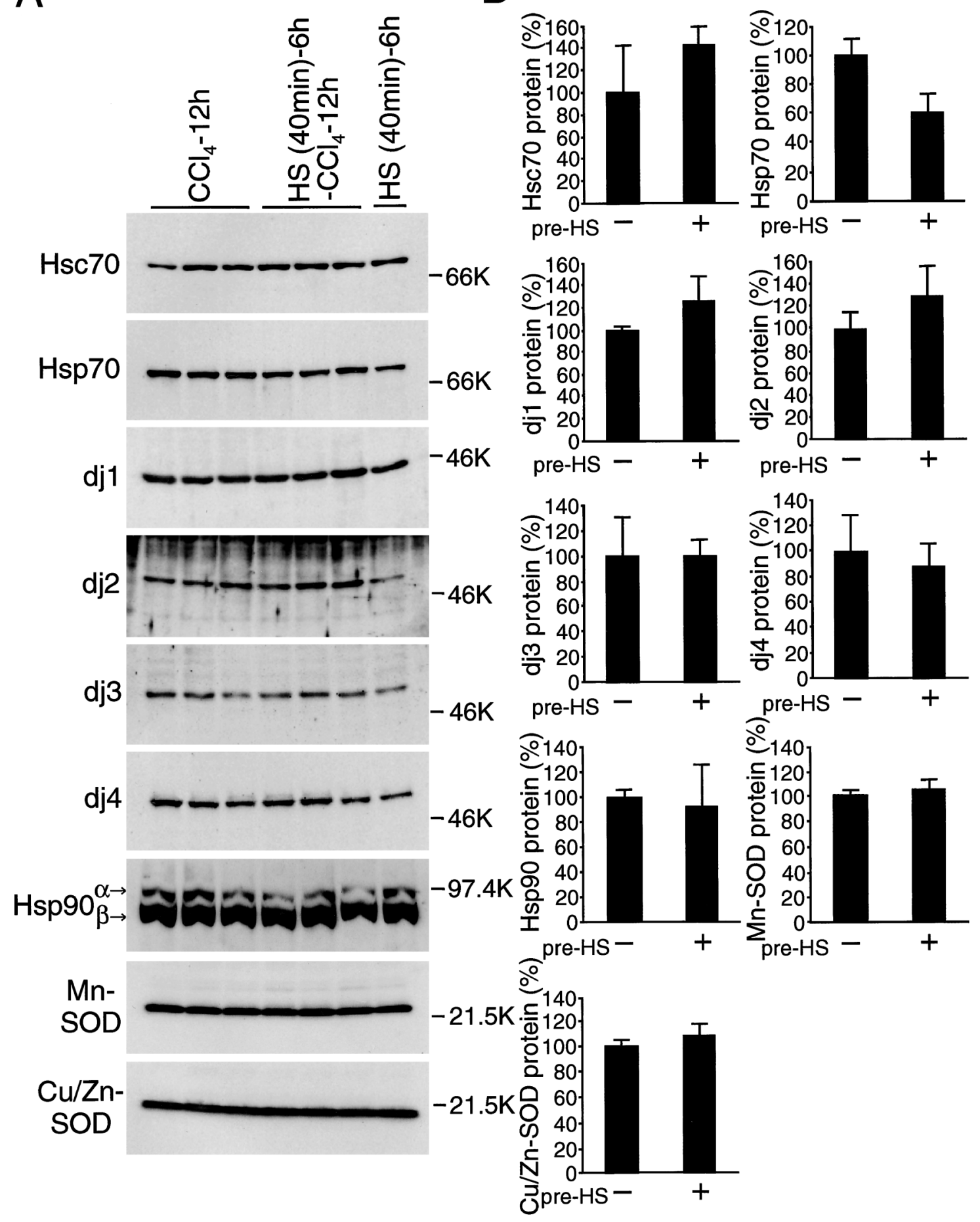

Fig 5. Induction of heat shock protein (Hsp) 70 and DnaJ chaperones in the carbon tetrachloride $\left(\mathrm{CCl}_{4}\right)$-treated rat liver with heat pretreatment. (A) and (C) Rats were heated at $42^{\circ} \mathrm{C}$ for 40 minutes and allowed to recover at room temperature for 6 hours or not heat treated. Next, $\mathrm{CCl}_{4}$ was given intraperitoneally or not given. After 12 hours $(\mathrm{A})$ or 24 hours $(\mathrm{C})$, liver extracts $(10 \mu \mathrm{g}$ of protein for heat shock cognate [Hsc] 70, Hsp70, dj1, dj2, Hsp90, Mn-superoxide dismutase [SOD], and Cu/Zn-SOD; $50 \mu \mathrm{g}$ of protein for dj3 and dj4) were subjected to immunoblot analysis for Hsc70, Hsp70, dj1, dj2, dj3, dj4, Hsp90, Mn-SOD, and Cu/Zn-SOD. Molecular weight markers are phosphorylase B $(97.4 \mathrm{kDa})$, bovine serum albumin $(66 \mathrm{kDa})$, ovalbumin $(46 \mathrm{kDa})$, and trypsin inhibitor $(21.5 \mathrm{kDa})$. (B) and (D) The results of CCl -treated $^{-}$ rats with or without heat treatment in (A) and (C) were quantified and are shown as means $\pm \mathrm{SD}(n=3)$, respectively. Maximal values of $\mathrm{CCl}_{4}$-treated rats without heat treatment are set at $100 \%$. (E) Rats were heated at $42^{\circ} \mathrm{C}$ for 40 minutes and allowed to recover at room temperature for 6 hours (filled circle) or not heat treated (open circle). Then, $\mathrm{CCl}_{4}$ was injected intraperitoneally. At indicated times after $\mathrm{CCl}_{4}$ $(1.0 \mathrm{~mL} / \mathrm{kg}$ injection, serum ALT activity was measured, and the results are shown as means $\pm \mathrm{SE}(n=3)$. ALT, alanine aminotransferase. 
C

D

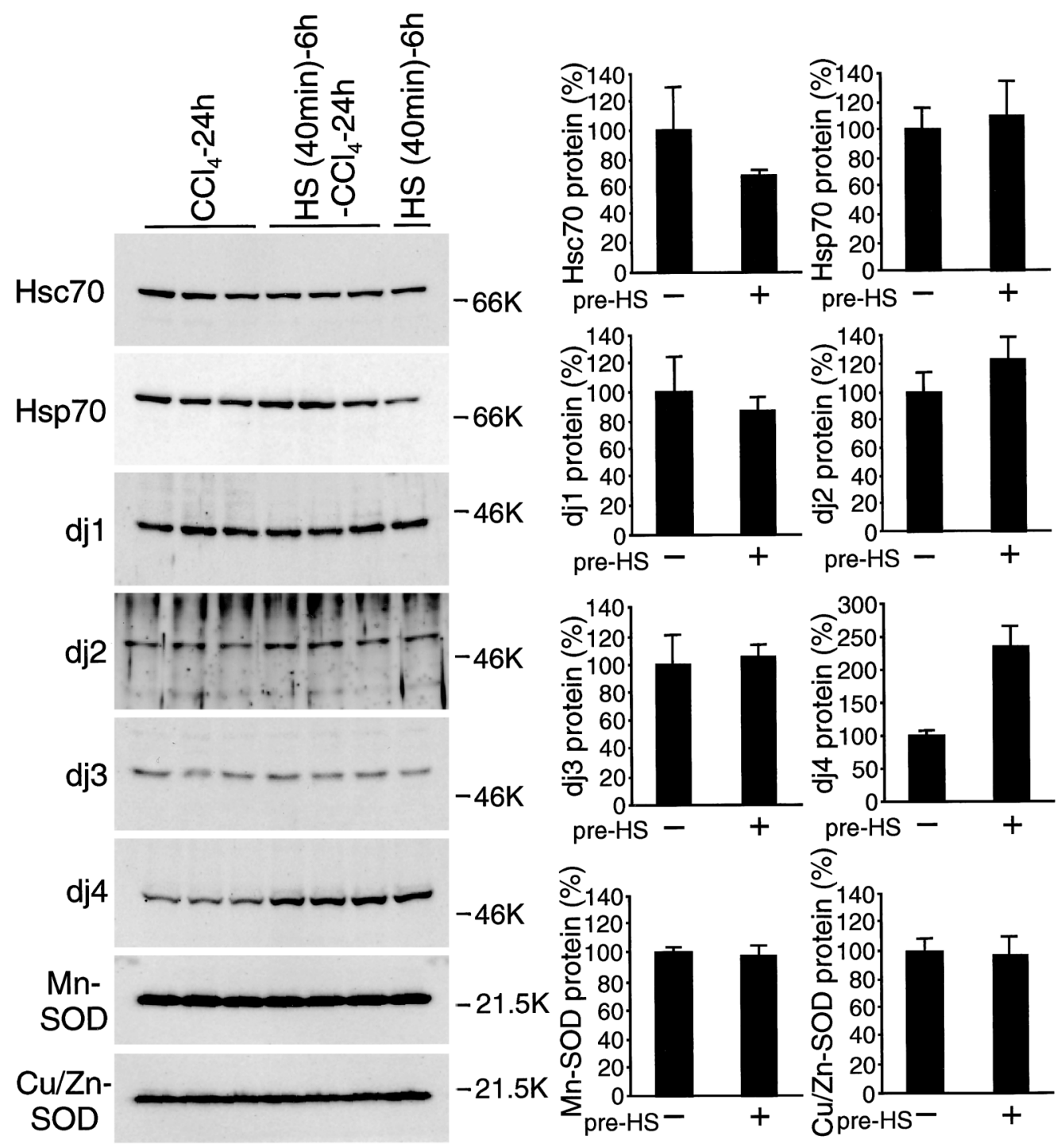

$E$

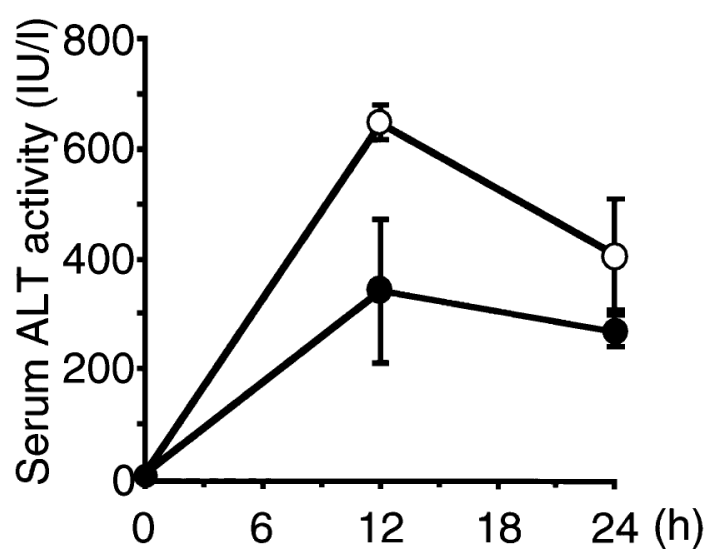

Fig 5. Continued. 
the treatment, began to increase at 3 hours, and then increased gradually. On the other hand, Hsp70 protein, which was undetectable before treatment, began to increase at 6 hours after treatment, reached a maximum at 12 hours, and then decreased sharply. dj1, dj2, and dj4 proteins, which were detectable at low levels before treatment, began to increase at 6 hours, reached a maximum at 12 hours, decreased gradually thereafter, and then reached a control level at 48 hours. dj3 protein, which was detectable at low levels before treatment, was weakly induced up to 48 hours. AL protein, which was used as control, remained little changed by the $\mathrm{CCl}_{4}$ treatment. These results show that $\mathrm{CCl}_{4}$ treatment induces all members of cytosolic Hsp70 and DnaJ families in rat liver. Among these members, Hsp70 and dj1 were induced strongly, dj2 and dj4 moderately, and Hsc70 and dj3 weakly. For reasons unknown, inductions of Hsc70, dj1, dj2, and dj4 proteins (about 1.7-, 6.2-, 2.0-, and 2.3-fold, respectively) were much lower than those of respective mRNAs (about 5.1-, 28.7-, 11.9-, and 22.2-fold, respectively). This discrepancy may be due to the decrease in translation of their mRNAs or to an increase in degradation of these proteins after $\mathrm{CCl}_{4}$ treatment.

\section{Heat pretreatment induces Hsps in rat liver and prevents $\mathrm{CCl}_{4}$-induced liver damage}

Hsp70 or Hsp70-DnaJ chaperone pairs protect cells from various stresses. We speculated that Hsp70 and DnaJ chaperones are induced by $\mathrm{CCl}_{4}$ to protect hepatocytes from $\mathrm{CCl}_{4}$-induced damage. We then speculated that Hsp70-DnaJ chaperone pairs induced before $\mathrm{CCl}_{4}$ treatment will suppress liver damage. To test this, we examined the effect of heat pretreatment of rats on $\mathrm{CCl}_{4}$-induced liver damage. Figure 4A shows induction of Hsp70 in the liver by whole-body heat treatment of rats. Animals were heat treated for 20,40 , or 60 minutes at $42^{\circ} \mathrm{C}$ and then allowed to recover for 6 hours at room temperature. Hsp70 was induced weakly by treatment for 20 minutes, strongly by treatment for 40 minutes, and less strongly by treatment for 60 minutes. The induction by 40 -minute treatment was higher than that at 12 hours after $\mathrm{CCl}_{4}$ treatment. Thus, heat pretreatment for 40 minutes was used in the following experiments.

Induction of chaperones by heat treatment is shown in Figure 4B,C. Hsp70 was induced markedly, dj1 and dj4 moderately. Hsc70, dj2, and dj3 were not induced. Hsp90 is 1 of the major mammalian cytosolic molecular chaperones, and its antiapoptotic effects have been reported (Pandey et al 2000; Garrido et al 2001). Hsp90 was induced moderately by heat treatment (Fig 4B).

Antioxidant activities are closely related with $\mathrm{CCl}_{4}$-induced lipid peroxidation (Wolfgang et al 1990; Sato et al 1995). SOD is 1 of the important intracellular antioxidant enzymes. Schiaffonati and Tiberio (1997) reported that $\mathrm{Mn}-\mathrm{SOD}$ and $\mathrm{Cu} / \mathrm{Zn}-\mathrm{SOD}$ are induced by $\mathrm{CCl}_{4}$ treatment in rat liver, as well as Hsp70s. However, these enzymes were not induced by heat treatment (Fig 4B).

To examine the effect of preinduced chaperones before $\mathrm{CCl}_{4}$ injection, rats were heat-pretreated and then subjected to $\mathrm{CCl}_{4}$ treatment. Levels of chaperones in heatpretreated and untreated animals 12 and 24 hours after $\mathrm{CCl}_{4}$ injection are shown in Figure 5A-D. Levels of all chaperones including Hsc70, Hsp70, dj1, dj2, dj3, dj4, and Hsp90 were similar between heat-treated and untreated animals, except that dj4 was higher in heat-pretreated animals 24 hours after $\mathrm{CCl}_{4}$ treatment. Levels of Mn-SOD and $\mathrm{Cu} / \mathrm{Zn}-\mathrm{SOD}$ proteins were similar between heattreated and untreated animals. Those levels were also similar to the levels in heat-treated animals.

Histopathological studies of rat liver after $\mathrm{CCl}_{4}$ treatment showed little difference between with and without heat pretreatment (data not shown).

Figure 5E shows the effect of heat pretreatment on serum ALT activity. Increase in ALT activity was suppressed by heat pretreatment by about 53\% at 12 hours after $\mathrm{CCl}_{4}$ treatment and by about $66 \%$ at 24 hours. Because levels of chaperones in heat-untreated and heat-pretreated animals were similar at 12 and 24 hours after $\mathrm{CCl}_{4}$ treatment, these results suggest that chaperones preinduced by heat pretreatment protect hepatocytes from $\mathrm{CCl}_{4}$-induced damage at early stages of $\mathrm{CCl}_{4}$ treatment. These results also suggest that $\mathrm{Hsp} 70$ and DnaJ chaperones are induced in rat liver by $\mathrm{CCl}_{4}$ treatment to protect hepatocytes from $\mathrm{CCl}_{4}$-induced damage.

\section{DIscussion}

The mechanism of cytoprotection by Hsp70 is generally explained by the notion that Hsp70 binds to damaged and misfolded proteins and facilitates refolding or targets severely damaged proteins for degradation (Kampinga 1993; Stege et al 1994; Samali and Orrenius 1998). Hsp70 protects cells from various stresses, including apoptosisinducing stresses and agents, such as oxidative stress, nitric oxide, tumor necrosis factor, anticancer drugs, ceramide, and radiation (Samali and Orrenius 1998). In hepatocytes, Hsp70 was reported to protect cells from tumor necrosis factor $-\alpha$, prostaglandin, hydrogen peroxide, ethanol, or ultraviolet C (Kim et al 1997; Ahn et al 1998; Chen et al 1999; Ikeyama et al 2001). Although antiapoptotic effects of Hsp70 have been repeatedly reported, related mechanisms are unclear. Polla et al (1996) reported that Hsp70 provides antiapoptotic effects upstream of the intrinsic pathway by blocking the effect of factors to induce cytochrome $c$ release. In contrast, Jäättelä et al (1998) suggested that the site of Hsp70 action is downstream of caspase- 3 activation in tumor necrosis factor- $\alpha$-induced 
apoptosis. Using in vitro systems, Hsp70 was reported to prevent formation of functional apoptosome (Beere et al 2000). In heat-induced cell death, Hsp70 was reported to inhibit the activation of stress-activated protein kinase cJun N-terminal kinase and processing of procaspase-3 (Mosser et al 1997).

Shi et al (1998) reported that apoptosis in the rat liver was observed histochemically after $\mathrm{CCl}_{4}$ administration. Sun et al (2001) reported that the activity of caspase-3 was increased in the rat liver and plasma after $\mathrm{CCl}_{4}$ administration. Schiaffonati and Tiberio (1997) reported that Hsp70 is induced in acute liver damage by $\mathrm{CCl}_{4}$ and that heat shock transcription factor is activated. In this study, we found that not only Hsp70 but also Hsc70 and DnaJ homologs are induced in $\mathrm{CCl}_{4}$-treated rat liver. Induction of Hsc70 is notable because it is known to be little induced by various stresses. All these chaperones are induced through similar kinetics, and it is likely that these chaperones are induced by activation of a heat shock transcription factor. If this is indeed the case, it remains to be elucidated how $\mathrm{CCl}_{4}$ activates heat shock transcription factor.

DnaJ family members are known to function as cochaperones by stimulating adenosine triphosphatase activity of Hsp70 in protein folding (Bukau and Horwich 1998; Kelley 1998; Terada and Mori 2000). We found that dj1 or dj2 is essential for the antiapoptotic function of Hsp70 and that the Hsp70-DnaJ chaperone pairs exert antiapoptotic effects upstream of cytochrome $c$ release from mitochondria in nitric oxide-induced apoptosis (Gotoh et al 2001). However, the precise mechanism of how the DnaJ homolog cooperates with Hsp70 to protect cells from apoptosis is unknown. Further studies are needed to elucidate how Hsp70-DnaJ chaperone pairs prevent liver damage caused by $\mathrm{CCl}_{4}$. We also showed that Hsp90 is moderately induced by heat pretreatment. Therefore, Hsp90 may also be involved in the protection against $\mathrm{CCl}_{4}$-induced liver damage. Salminen et al (1997) reported that Hsp induction did not afford protection from $\mathrm{CCl}_{4}$ hepatotoxicity in mice. Whether this difference is due to species difference or to other factor(s) is not known.

Our results show that $\mathrm{Mn}-\mathrm{SOD}$ and $\mathrm{Cu} / \mathrm{Zn}-\mathrm{SOD}$ are not induced by either heat-treatment or $\mathrm{CCl}_{4}$ treatment. This agrees with the previous report that SOD activity is not induced in mouse liver by whole-body hyperthermia (King et al 2002). Although Schiaffonati and Tiberio (1997) reported that $\mathrm{Mn}-\mathrm{SOD}$ and $\mathrm{Cu} / \mathrm{Zn}-\mathrm{SOD}$ mRNAs are induced in rat liver around 24 hours after $\mathrm{CCl}_{4}$ treatment, this induction is much later than when the liver damage occurs (Fig 1B). These results suggest that SOD is not important in the protection of $\mathrm{CCl}_{4}$-induced liver damage.

Clinically, liver injury caused by drugs and toxins is most common disease. Although severe liver injury is occasionally lethal, an effective therapy has not been established, except for liver transplantation. Induction of Hsp70-DnaJ chaperone pairs may eventually prove therapeutic for liver injury. Development of efficient and safe procedures to induce Hsp70-DnaJ chaperone pairs is waited.

\section{ACKNOWLEDGMENTS}

This work was supported in part by Grants-in-Aid (14370047 to M.M. and 13670124 to T.G.) from the Ministry of Education, Science, Technology, Sports, and Culture of Japan and a grant (to T.G.) from Takeda Science Foundation. We thank our colleagues for suggestions and discussion and M. Ohara (Fukuoka, Japan) for comments on the manuscript.

\section{REFERENCES}

Abdul KM, Terada K, Gotoh T, Hafizur RM, Mori M. 2002. Characterization and functional analysis of a heart-enriched DnaJ/ Hsp40 homolog dj4/DjA4. Cell Stress Chaperones 7: 156-166.

Ahn SG, Jeong SY, Rhim H, Kim IK. 1998. The role of c-Myc and heat shock protein 70 in human hepatocarcinoma Hep3B cells during apoptosis induced by prostaglandin A2/Delta12-prostaglandin J2. Biochim Biophys Acta 1448: 115-125.

Beere HM, Wolf BB, Cain K, et al. 2000. Heat-shock protein 70 inhibits apoptosis by preventing recruitment of procaspase- 9 to the Apaf-1 apoptosome. Nat Cell Biol 2: 469-475.

Bukau B, Horwich AL. 1998. The Hsp70 and Hsp60 chaperone machines. Cell 92: 351-366.

Chen YC, Lin-Shiau SY, Lin JK. 1999. Involvement of heat-shock protein 70 and P53 proteins in attenuation of UVC-induced apoptosis by thermal stress in hepatocellular carcinoma cells. Photochem Photobiol 70: 78-86.

Chomczynski P, Sacchi N. 1987. Single-step method of RNA isolation by acid guanidinium thiocyanate-phenol-chloroform extraction. Anal Biochem 162: 156-159.

Garrido C, Gurbuxani S, Ravagnan L, Kroemer G. 2001. Heat shock proteins: endogenous modulators of apoptotic cell death. Biochem Biophys Res Commun 286: 433-442.

Gotoh T, Terada K, Mori M. 2001. hsp70-DnaJ chaperone pairs prevent nitric oxide-mediated apoptosis in RAW 264.7 macrophages. Cell Death Differ 8: 357-366.

Ikeyama S, Kusumoto K, Miyake H, Rokutan K, Tashiro S. 2001. A non-toxic heat shock protein 70 inducer, geranylgeranylacetone, suppresses apoptosis of cultured rat hepatocytes caused by hydrogen peroxide and ethanol. J Hepatol 35: 53-61.

Jäättelä M, Wissing D, Kokholm K, Kallunki T, Egeblad M. 1998. Hsp70 exerts its anti-apoptotic function downstream of caspase-3-like proteases. EMBO J 17: 6124-6134.

Johnson JL, Craig EA. 1997. Protein folding in vivo: unraveling complex pathways. Cell 90: 201-204.

Kampinga HH. 1993. Thermotolerance in mammalian cells. Protein denaturation and aggregation, and stress proteins. J Cell Sci 104: 11-17.

Kelley WL. 1998. The J-domain family and the recruitment of chaperone power. Trends Biochem Sci 23: 222-227.

Kim YM, de Vera ME, Watkins SC, Billiar TR. 1997. Nitric oxide protects cultured rat hepatocytes from tumor necrosis factor- 
alpha-induced apoptosis by inducing heat shock protein 70 expression. J Biol Chem 272: 1402-1411.

King YT, Lin CS, Lin JH, Lee WC. 2002. Whole-body hyperthermiainduced thermotolerance is associated with the induction of heat shock protein 70 in mice. J Exp Biol 205: 273-278.

Lindquist S, Craig EA. 1988. The heat-shock proteins. Annu Rev Genet 22: 631-677.

Mosser DD, Caron AW, Bourget L, Denis-Larose C, Massie B. 1997. Role of the human heat shock protein hsp70 in protection against stress-induced apoptosis. Mol Cell Biol 17: 5317-5327.

Netzer WJ, Hartl FU. 1998. Protein folding in the cytosol: chaperonin-dependent and -independent mechanisms. Trends Biochem Sci 23: 68-73.

Ohtsuka K, Hata M. 2000. Mammalian HSP40/DNAJ homologs: cloning of novel cDNAs and a proposal for their classification and nomenclature. Cell Stress Chaperones 5: 98-112.

Oyadomari S, Gotoh T, Aoyagi K, Araki E, Shichiri M, Mori M. 2001. Coinduction of endothelial nitric oxide synthase and arginine recycling enzymes in aorta of diabetic rats. Nitric Oxide 5: 252260.

Pandey P, Saleh A, Nakazawa A, et al. 2000. Negative regulation of cytochrome $c$-mediated oligomerization of Apaf- 1 and activation of procaspase-9 by heat shock protein 90. EMBO J 19: 43104322.

Parsell DA, Lindquist S. 1993. The function of heat-shock proteins in stress tolerance: degradation and reactivation of damaged proteins. Annu Rev Genet 27: 437-496.

Polla BS, Kantengwa S, Francois D, Salvioli S, Franceschi C, Marsac C, Cossarizza A. 1996. Mitochondria are selective targets for the protective effects of heat shock against oxidative injury. Proc Natl Acad Sci U S A 93: 6458-6463.

Salminen WF Jr, Voellmy R, Roberts SM. 1997. Protection against hepatotoxicity by a single dose of amphetamine: the potential role of heat shock protein induction. Toxicol Appl Pharmacol 147: 247-258.

Samali A, Orrenius S. 1998. Heat shock proteins: regulators of stress response and apoptosis. Cell Stress Chaperones 3: 228-236.
Sato M, Sasaki M, Hojo H. 1995. Antioxidative roles of metallothionein and manganese superoxide dismutase induced by tumor necrosis factor-alpha and interleukin-6. Arch Biochem Biophys 316: 738-744.

Schiaffonati L, Tiberio L. 1997. Gene expression in liver after toxic injury: analysis of heat shock response and oxidative stress-inducible genes. Liver 17: 183-191.

Shi J, Aisaki K, Ikawa Y, Wake K. 1998. Evidence of hepatocyte apoptosis in rat liver after the administration of carbon tetrachloride. Am I Pathol 153: 515-525.

Smith DF, Whitesell L, Katsanis E. 1998. Molecular chaperones: biology and prospects for pharmacological intervention. Pharmacol Rev 50: 493-514.

Stege GJ, Li L, Kampinga HH, Konings AW, Li GC. 1994. Importance of the ATP-binding domain and nucleolar localization domain of HSP72 in the protection of nuclear proteins against heatinduced aggregation. Exp Cell Res 214: 279-284.

Sun F, Hamagawa E, Tsutsui C, Ono Y, Ogiri Y, Kojo S. 2001. Evaluation of oxidative stress during apoptosis and necrosis caused by carbon tetrachloride in rat liver. Biochim Biophys Acta 1535: 186-191.

Terada K, Kanazawa M, Bukau B, Mori M. 1997. The human DnaJ homologue dj2 facilitates mitochondrial protein import and luciferase refolding. J Cell Biol 139: 1089-1095.

Terada K, Mori M. 2000. Human DnaJ homologs dj2 and dj3, and bag-1 are positive cochaperones of hsc70. J Biol Chem 275: 24728-24734.

Williams AT, Burk RF. 1990. Carbon tetrachloride hepatotoxicity: an example of free radical-mediated injury. Semin Liver Dis 10: 279-284.

Wolfgang GH, Jolly RA, Donarski WJ, Ochoa R, Petry TW. 1990. Inhibition of carbon tetrachloride-induced lipid peroxidation by novel antioxidants in rat hepatic microsomes: dissociation from hepatoprotective effects in vivo. J Biochem Toxicol 5: 167-174.

Yu Y, Terada K, Nagasaki A, Takiguchi M, Mori M. 1995. Preparation of recombinant argininosuccinate synthetase and argininosuccinate lyase: expression of the enzymes in rat tissues. J Biochem (Tokyo) 117: 952-957. 